\title{
Issues Concerning the Eradication or Establishment and Biological Control of the Mediterranean Fruit Fly, Ceratitis capitata (Wiedemann) (Diptera: Tephritidae), in California
}

\author{
David H. Headrick and Richard D. Goeden \\ Department of Entomology, University of California, Riverside, California 92521
}

Classical biological control is suggested as a tool worth developing now for possible future use in the integrated pest management of the Mediterranean fruit fly (Medfly), Ceratitis capitata (Wiedemann), in California. Three factors that impact broadly on developing and implementing such a biological control program are: (1) the question of Medfly establishment, (2) quarantine considerations, and (3) agricultural and urban concerns. Each of these factors and their combined effects must be considered when discussing biological control of Medfly in California as shaped by historical perspectives on Medfly invasions, methods of Medfly eradication, and past biological control efforts against Medfly. We believe that biological control research should play a foundational role in any future Medfly management programs in California. Development of biological control should involve life history studies of Medfly and its natural enemies in their area of endemicity in sub-Saharan, southeast Africa. Medfly has been studied and should continue to be studied in areas it has invaded, because information derived from such studies provides insights into the potential distribution, abundance, and impact of Medfly populations in California. A plan for a biological research program on Medfly and its relatives and a biological control strategy are presented.

KEY WoRds: Ceratitis capitata; Medfly; biological control; eradication; establishment; life history; quarantine; history; Aceratoneuromyia indica; Anastrepha suspensa; Bactrocera dorsalis; Capsicum frutescens; Ceratitis rosa; Chrysophyllum sp., Diachasmimorpha Iongicaudatus; Doryctobracon areolatus; Eutreta simplex; Opius bellus; Paracantha genalis; Pteromalus coloradensis; Rhagoletis completa; Trirhithrum coffeae; Steinernema fel tiae.

Biological control research on the Mediterranean fruit fly (hereafter Medfly), Ceratitis capitata (Wiedemann) (Diptera: Tephritidae) should be undertaken now, by and for California. At the very least, biological control research invariably yields important knowledge on the biology and ecology of a target pest, in addition to the obvious benefits of research on the pest's natural enemies, i.e., predators, parasitoids, and pathogens, sought for use as biological control agents. Biological control research on Medfly will add much useful knowledge to the Medfly biological database that in the short term may aid the development of new eradication and monitoring methods. In the long term, this knowledge will facilitate the development and implementation of integrated pest management (IPM) of M edfly in California, whatever the future status of this pest may be.

At present, detection and eradication of the Medfly in California continues year after year and is a highly charged political issue as well as a topic of scientific dispute. Rarely have public concerns about theenvironmental effects of insect control methods as well as federal, state, and local politics so influenced the way in which research and development funding is appropriated and allocated. Also, rarely has the question of insect pest establishment been so polarized and disputed so heatedly as with the Medfly. The policy debate on Medfly establishment in California exists because of the threat of foreign and domestic quarantines on California's fruits and vegetables, the need to justify State and Federal funding to continue an eradication program, and concerns of agricultural versus urban human populations. However, funding for biological control research on Medfly in California is hampered by the attitude that biological control research can only be conducted on an established pest, not in anticipation of pest establishment. As a consequence, supporting biological control of Medfly also implies defeat for the Medfly eradication program. We dismiss this attitude as narrow and misplaced. Biological control research on Medfly in reality is an investment in the acquisition of biological and ecological knowledge needed for both 
short- and long-term management of what promises to be a long-term problem in California.

This position paper on Medfly examines the literature relating to the biological control of Medfly. A thorough review of all of the literature on the Medfly would be an enormous task and is not attempted herein. Instead, we highlight reports that give insight into the biological control of Medfly and how previous lessons may be applied to the California situation. The paper is divided into two sections. In the first section, three factors are discussed which impact on research and management of Medfly in California: (1) the question of Medfly establishment, (2) foreign and domestic quarantine considerations, and (3) agricultural versus urban concerns. In the second section, the collective impact of these three factors is discussed relative to biological control of Medfly. Every biological control program is unique and each requires thoughtful consideration of biological and socially relevant variables involved before, while, and after the work is undertaken.

\section{FACTORS INFLUENCING MEDFLY MANAGEMENT IN CALIFORNIA}

\section{Factor 1: TheQuestion of Establishment}

Is Medfly established in California? This question has been heatedly debated during the past few years in several arenas, including the popular press and the California Senate. Principal participants have been Dr. J ames Carey, Professor of Entomology at the University of California Davis, (Carey and Dowell, 1989; Carey 1991, 1992) and representatives of the California Department of Food and Agriculture (CDFA). Carey believes the Medfly is established in California and provided compelling circumstantial evidence (Carey 1991, 1992) for considering the invasion and establishment of Medfly in California as reflecting a "classical" process for an exotic pest. However, using the same data set, the CDFA (1994) maintained instead that successive, newly founded Medfly colonies were successfully eradicated and that each new find represented a new invasion.

Further examination of the evidence to date in light of these two hypotheses, invasion and establishment and recurrent invasion, is provided. Medfly occurrence in North America has been sporadic. For example, northern California had a serious infestation in 1980 and again in 1989; similarly, Florida was invaded in 1929 and again in 1956. This disparity between dates of invasion by Medfly may reflect where the United States has had border inspection services specifically looking for this pest since the early part of this century (Zadig, 1992). New research using genetic markers of known Medfly populations has shown that Medflies occurring in California are not from Hawaii (Sheppard et al.,
1992), but the data are inconclusive for an actual source(s) of California's Medfly invasions. Thus, the question of Medfly establishment in California persists, but the evidence, in our opinion, is building against the case for recurrent invasions. We believe that California can no longer ignore the inevitability of recurrent Medfly populations. The State must prepare to deal with the eventuality and consequences of permanent Medfly populations.

Final proof of establishment of Medfly populations in California will require detection and collection of persistent, reproducing, Medfly populations. A persistent population is one that can be collected from year to year and all of its life stages can be followed through consecutive generations or collected from predictable locations. This task is yet to be fulfilled.

But why? We may look to our native tephritid fruit flies for clues. Our studies of tephritids in southern California have demonstrated that some species of tephritids can persist in extremely low numbers. For example, fewer than one dozen adults of the tephritids Paracantha genalis Malloch and Eutreta simplex Thomas have been collected during the past decade from known host plants in readily accessible, known, but circumscribed localities (Goeden, 1990b, Headrick and Goeden, 1990a). Low-density Medfly colonies could similarly escape detection by present trapping methods. According to Steiner et al. (1961), while monitoring Medfly populations during the 1956 invasion of Florida, unusually high numbers of Medfly adults were trapped just before a storm. These sudden increases in catches fortuitously warned that far more flies were present in infested areas than indicated by previous trap catches.

The host-plant range of the Medfly is broad, with 180 plant species verified as hosts in Hawaii (Liquido et al., 1990); therefore, potential hosts are abundant in the diverse, cultivated and uncultivated flora of California and pose the eventuality of Medfly "population cycling." Population cycling is known among several, native, nonfrugivorous (non-fruit-feeding) tephritids in southern California. This cycling is characterized by different host-plant species sequentially serving as fruit fly reproductive hosts for parts of the year (see below). Given the lack of diapause in many frugivorous tephritids and their wide host ranges, population cycling on alternate hosts could play a major role in the eventual successful establishment of and future economic depredations of exotic fruit flies such as the Medfly in California (Siebert and Pradhan, 1990).

Studies of native tephritid populations in southern California show that wide-ranging adult fly dispersal and host cycling is a common life history strategy (Goeden 1987, 1988a, b; Goeden and Headrick 1990, 1991a, b, 1992; Green et al., 1993; Headrick and Goeden, 1990a, b, 1991; Goeden et al., 1993, 1994a, b; Headrick et al., 1993, 1995). Where Medflies have 
successfully invaded a country, such as Guatemala, they also have dispersed widely areawise (50-80 km²) and altitudinally (sea-level to $1000 \mathrm{~m}$ ) in search of hosts suitable for oviposition (Eskafi and Kolbe, 1990). Medfly populations in South Africa also move from one area to another depending on host-plant availability, and they cycle through host after host during the entire year (Annecke and Moran, 1982). Since December 1993, over 400 Medflies have been trapped and dozens of larvae recovered from fruits confiscated at ports of entry in southern California. Three hundred and seventy-nine of the $400+$ adults were trapped at new locations (CDFA, 1994). Adults were trapped in 1994 for the first time in Ventura Co. These collections suggest, irrespective of the size of the outbreak, that Medfly is spreading eastward and westward from the location where adults were originally collected in the Los Angel es basin in the 1970s and 1980s (Carey, 1991).

Our view on the establishment issue can be summarized as follows; two diametrically opposed facts remain unchallenged: (1) The Medfly exhibits chronic occurrence in southern California, and (2) no one has yet discovered a local breeding population of Medflies in California. The fact that Medfly has chronic occurrence in southern California may make the establishment issue somewhat irrelevant, but it has a strong negative impact on the ability of California scientists to conduct biological control research on what is defined as a nonresident pest.

\section{Factor 2: The Threat of Quarantine}

Quarantine of California's agricultural products is a serious concern for the citizens of California. California ranks first among all states in agricultural production in 68 of its 250 crops (CDFA, 1993), and produces half of all U.S. fruit, nuts, and vegetables on only $3 \%$ of the total U.S. farmland. In the San J oaquin Valley, $30 \%$ of personal income and $10 \%$ of all jobs are related to agriculture (Siebert and Pradhan, 1990). Overall, the agricultural industry in California is worth \$17-18 billion annually. California has intermittent problems with overseas markets limiting or denying shipment of fruits and vegetables. In 1980, 100 million dollars were lost due to a J apanese embargo on California fruits resulting from Medfly finds that year, and J apanese authorities expressed alarm over a Medfly find on December 17, 1993, in Corona, in Riverside Co. If the Medfly were declared established and quarantines were imposed against California fruit and vegetables, the worst-case scenario could be the statewide loss of over 14,000 agriculturally related jobs and \$1.06-1.44 billion in revenues (Siebert, 1994). Quarantines by overseas markets probably would include J apan, Taiwan, Hong Kong, Singapore, and Malaysia; domestic quarantines would likely be enacted by Arizona, Texas, and Florida (Siebert and Pradhan, 1990; Siebert, 1994).
Further restrictions by domestic and overseas markets are inevitable if research funding actions show or are interpreted that Medfly or other exotic fruit flies are established in California. The constant threat of quarantine against California commodities on the world market, therefore, also inhibits the development and funding of biological control research against invading pest species like the Medfly.

The global distribution of the Medfly has been summarized by White and Elson-Harris (1992). Medflies have also been collected throughout Asia Minor (Froggatt, 1909; Silvestri, 1914), and Zia (1937) states that Medflies probably occur throughout tropical Asia. However, this is an issue which deserves further research. Congeners and closely related genera have been reported throughout much of Asia, Asia Minor, Micronesia, and Polynesia (Hendel, 1912; Shiraki, 1933; Munro, 1935; Zia, 1937, 1938; Hardy, 1973, 1974; White and Elson-Harris, 1992; Foote et al., 1993). These Asian collection records of Ceratitis and related genera and the otherwise global distribution of Medfly need verification, but may indicate its presence, albeit rare, throughout Asia.

Quarantine of California fruits and vegetables by Asian markets should not be based on preventing the introduction of Medfly via California fruit and vegetables. Rather, they should be based on containment and fumigation in California. As an example, California stone fruit were quarantined by New Zealand in the late 1980s because it was reported that the walnut husk fly, Rhagoletis completa Cresson, was found to reproduce in some types of stone fruit. In response, funds from several state and federal agencies in the United States were devoted to devising fumigation and cold treatments of stone fruit, and establishment of pest-free periods and fumigation controls (Yokoyama et al., 1992). Florida has used the approach of a pest-free zone to minimize quarantine losses to the Caribbean fruit fly, Anastrepha suspensa (Loew). Florida agricultural officials negotiated with foreign and domestic buyers to accept fruit from areas that have been treated with ground spraying and fruit stripping. This approach works well with Caribbean fruit fly because its host range is mostly limited to guava. However, such an approach would be far more difficult with Medfly in California.

All southern United States in the so-called "sun-belt" are vul nerable to Medfly invasion, and cooperation, not exploitation, is in the best long-term interest of all.

\section{Factor 3: Agricultural and U rban Concerns}

A serious concern is the differing views on Medflies held by the California agricultural community and urban communities affected by Medfly. Like other North American pest invasions, the Medfly invasion in southern California involves interspersed and contigu- 
ous natural, urban, and agricultural environments. The CDFA contends that Medfly populations are reintroduced into urban and agricultural areas (Carey and Dowell, 1989). These populations are addressed by some stripping of backyard fruit, spot treatments, aerial spraying of malathion, and local quarantines of fruits and vegetables. However, these methods of control are invasive and cause public concern (Hawkes and Stiles, 1985).

Concerns of the urban community aretypically voiced by small and politically fractured, special-interest groups. They have raised eradication officials' and researchers' awareness of human fears and perceived hazards of aerial bait sprays. In response to citizen concerns voiced in 1990, the CDFA brought together government and university researchers from around the nation to discuss and prioritize future research alternatives to malathion containing sprays (Advances in Medfly and Mexican Fruit Fly Detection's and Eradication Methodology: Future Directions for Research, 16-17 October 1991, University of California, Davis). Although several research areas, including hightechnology, "biorational" control methods (e.g., pheromone research), were given high priority, proposals for biological control research did not receive funding. Malathion was held to be California's best alternative for Medfly eradication and control. More recently, the University of California brought together a similar group of researchers, again seeking to prioritize research for alternatives to using malathion for Medfly eradication in California (Metcalf, 1995). In our opinion, detection and eradication technology did not advance significantly during the 4-year interval between these workshops. Again, biological control research was not funded.

Civic satisfaction and trust has substantially eroded regarding the state government's ability to detect and eradicate the Medfly with a minimum of real or perceived harm. Pending lawsuits filed by cities subjected to poisoned-bait sprays may have a significant effect on the ability of the CDFA to respond quickly to any future Medfly infestations. The consequences of such delays would be enormous.

\section{ISSUES CONCERNING THE USE OF BIOLOGICAL CONTROL}

The preceding section defined and discussed factors related to Medfly eradication and control in California. The following discussion treats issues raised about biological control research within the scientific and regulatory communities, specifically those related to the efficacy of biological control agents against Medfly and other exotic tephritids in California.

\section{A. Historical Perspectives on Medfly Invasion} and Eradication

Invasion. Medfly was first noticed as a pest in fruit sent from the Azores to England in 1829 (MacLeay, 1829), and as a pest on Malta as early as, perhaps, 1820 (Compere, 1912). The Medfly was soon reported as a pest in Spain (1842), Algeria (1858), I taly (1863), Sicily (1878), Tunis (1885), and South Africa (1889) (Back, 1917). In 1890, it was discovered as a pest of peaches in Bermuda by C. V. Riley and L. O. Howard (1891), prominent early American entomologists, but had been reported from Bermuda as early as 1865 (Compere, 1912). Medfly spread to Western Australia by 1897 and to eastern Australia in 1898, and in 1899 it was found in Tasmania (Froggatt, 1909). In 1900, it was found in peach orchards near Paris, France; in 1901, it was found in New Zealand and Brazil (Back, 1917). In 1904, it was reported as a pest in Egypt and in Asia Minor, and in 1905 in Argentina. Between 1910 and 1914, it was "discovered" in tropical Africa, but not reported as a pest. In 1910, it was discovered in Hawaii and occurred on every island in the chain within 2 years (Compere, 1912). George Compere, in J anuary, 1903, told newspapers that this fruit fly could very easily wipe out the fruit industry of California if not monitored closely. As early as 1917, the Medfly was intercepted at the port of San Francisco by quarantine officials. North America was first invaded in 1929 in Florida, but the Medfly was successfully eradicated. The next invasion in North America occurred in 1956 in Costa Rica (Christensen and Stone, 1956) and Florida (Steiner et al., 1961). Medfly infestations were again reported in Florida in 1962, 1963, and 1981; in Texas in 1966 (Cunningham et al., 1980); and in California in 1975, 1980, 1986-1991 (Carey, 1992) and again in 1992, 1993-1994. On or before 1956, the Medfly successfully established in South and Central America. Subse quently it established in southern Mexico, where it is contained by an ongoing mass-release effort of sterile flies and bait sprays (Oritz et al., 1984). As Gilstrap and Hart (1987) reported, the Medfly is able to survive and persist in areas as far north as $50^{\circ}$ north latitude.

The history of the Medfly's global invasion shows patterns often observed for other cosmopolitan, 20th century pests. The Medfly was new to science in the early 1820s, but was, according to MacLeay (1829), already recognized as a pest. During the next 100 years, the Medfly was reported as a new and destructive pest, often simultaneously from different and widely separated countries, e.g., Egypt and Argentina in 1904-1905. Within one century, the Medfly invaded nearly every major continent and island in the world.

Eradication. Poisoned bait sprays for Medfly control were tried with some success as early as 1911 in Hawaii. The spray consisted of lead ar senate, molasses, and water (Weinland, 1912). Interestingly, Weinland 
(1912) suggested that insect parasitoids would probably be best for Medfly control in Hawaii, as the pest was already well established and any hope for its eradication was lost. He also noted that "artificial" means of control such as bait sprays would be best for California, as the Medfly had not yet invaded there. This became a basic tenet of eradication programsinvading populations are more susceptible to eradication methods than well-established populations. The 1929 Medfly invasion of Florida serves as a good example. The Florida State Agriculture Department directed a massive campaign to eradicate the Medfly from the Orlando area in 1928-1929. This involved a coordinated effort among state and federal agencies, local growers, and researchers. The eradication effort utilized fruit stripping, and poisoned bait sprays were applied in a timely manner with the full cooperation of area growers. Theinfested area was quarantined within 15 days of discovery of the first Medfly. The quarantine was enforced by county traffic officers, city police, and the Florida National Guard. The state allocated an initial $\$ 50,000$, which was matched by the USDA. Two weeks later, Congress approved an additional $\$ 4,250,000$ to hel $p$ fund this eradication program. The infestation involved 1000 properties, including municipal properties, homes with small backyards, and commercial plantings. The area involved 4,850,000 ha producing $72 \%$ of F lorida's citrus crop. During the last 6 months of 1929, 2,670,994 cars were searched and 28,850 (1.1\%) were found to contain fruit or vegetables suitable as hosts of Medfly, which were confiscated. Over half a million crates of citrus fruit, host vegetables, and other potential hosts were destroyed by grinding followed by burial or steaming. Poisoned bait sprays were applied in all commercial groves and surrounding vegetation, and $30,923 \mathrm{~km}$ of roadside vegetation were sprayed. At the height of the effort, 533,000 to 582,000 ha of groves were sprayed week ly. In addition to the material destroyed by the salaried, official workforce, more was gathered by volunteer citizens groups, e.g., Boy Scouts and citrus growers; in other words, it was a total community effort. Within 8 months, 999 of the 1000 properties were no longer infested (Newell, 1930).

Eradication programs against fruit flies entered the modern era with the 1956 Medfly invasion of Florida. Although there were similarities with the 1929 invasion, 1956 marked the first use of artificial lures, which had only been developed months before. Malathionlaced bait sprays also were used in the 1956 invasion. As with the 1929 invasion, Medflies were found in the month of April in grapefruit orchards and eradication was declared to be complete after 19 months (Steiner et al., 1961). A major difference between the 1929 and 1956 programs was that the infestations in 1929 were in mostly rural areas, involving only Orlando as a major city. In 1956, much of the area affected was urban, including all of Miami. Traps were used in 1956 to locate infestations and monitor the progress of eradication. Steiner et al. (1961) noted that the use of baited traps to follow Medfly populations failed to detect several serious outbreaks of Medflies that had increased and spread to new areas. Already in 1956, Florida could not afford the manpower invoked in 1929, and instead employed only 800 paid workers and used few volunteers. Fruit destruction was the chief means of eradication in 1929, whereas chemical bait sprays were newly used in 1956, thus saving not only in manpower, but al so fruit. Very little fruit was destroyed in 1956. Public sentiment concerning aerial malathion bait sprays was similar in 1956 to that expressed presently in southern California (Lorraine and Chambers, 1989); i.e., aerial spraying was blamed for bird, animal, and bee mortality as well as for plant defoliation, failure of plants to flower, and a variety of human illnesses.

When the Medfly first arrived in California, its eradication also became the main priority (Lorraine and Chambers, 1989). The State-directed program re lied on monitoring, malathion bait sprays, limited sterile insect technique (SIT) (Cunningham et al., 1980), and fruit-stripping. Fruit-stripping worked well in eradicating Medfly from Florida in 1929, but the same measures in Western Australia failed to provide control (see below), apparently because the Medfly was al ready well established. Fruit-stripping is not considered effective today because stripping one host-plant species in one area only promotes infestation of alternate hosts in new localities (McDonald, 1987). Thus, eradication in California currently is an ongoing and costly program because of yearly reoccurrences of $\mathrm{Med}$ flies in traps and the use of bait sprays and SIT. The reaction of Medfly populations to the cessation of the present eradication program is unknown and difficult to predict due to conflicting data (Newell, 1930; Compere, 1912). Medfly populations may increase or may continue to persist at low densities for several years.

The SIT program with Medflies in southern Mexico is now used to stem the flow of this pest northward. In conjunction with monitoring with baited traps, strategic zones are marked for SIT releases and aerial bait sprays. Aerial bait sprays were relied upon to suppress wild Medfly populations over a wide area prior to SIT releases, with up to 60 such aerial treatments per invasion episode (Carey, 1992). Ground-based insecticide treatments were used for sporadic outbreaks in other zones. Although the northward movement of Medfly in Mexico was stopped, outbreaks occur regularly in areas being treated with SIT alone. Thus, SIT probably cannot completely control or contain Medfly populations unless used in conjunction with other methods. Recently it has been reported that sterile 
male Medflies are discriminated against in mating with wild females and are less effective than wild males in mating with sterile females (Whittier et al., 1992). Additionally, using only sterile males in SIT programs in coffee plantations in Hawaii has proven more effective in reducing the reproductive output of wild females than releasing both sterilized sexes (Mclnnis et al., 1994).

\section{B. Devel opment of a Biological Control Program}

Collation of biological data. Biological studies on the Medfly have been conducted in several parts of the world where the Medfly is pestiferous. Thus, this biological knowledge is derived from the study of populations living in environments in which they are not subject to the same influences as in their area of natural origin or endemicity or to the same factors which have led to their evolution. However, when developing a plan for biological control, gathering and collation of previously reported biological information at least provide a basis for identifying future research needs for Medfly IPM.

What biological attributes can be inferred from a pest like the Medfly that rapidly establishes in widely divergent ecological and climatic zones, yet is highly destructive in some invaded areas, e.g., the Mediterranean, Hawaii, Australia, and yet is barely noticeable in other regions, e.g., Brazil, Asia Minor, Central America, Europe, and parts of Africa? The Medfly is sympatric with a large complex of ceratitine and dacine species in tropical Africa (Hancock, 1984, 1985, 1987; White and Elson-Harris, 1992). The M edfly has a wide host range, but is easily displaced by competing species in certain invaded areas, e.g., the Oriental fruit fly, Bactrocera dorsalis in Hawaii (Bess, 1953) and the Natal fruit fly, Ceratitis rosa Karsch in Madagascar (Hancock, 1984). Here, the Medfly was displaced by both $\mathrm{B}$. dorsal is and C. rosa to higher elevations, where it was restricted to only a few host-plant species. However, Harris and Lee $(1987,1989)$ reported that 50 years after the introduction of Oriental fruit fly into Hawaii, the Medfly was no longer completely displaced altitudinally and coexisted in the same hosts, but the Oriental fruit fly remained the dominant species outnumbering Medfly ca. 60:1 in shared fruit. This situation was similar to that reported by Vargas et al . (1983) for Medfly and Oriental fruit fly populations on the island of Kauai, Hawaii. In both Hawai and Guatemala, the Medfly is found at elevations from sea level to $>2000 \mathrm{~m}$, and its distribution and abundance are highly variable, reflecting the different distributions, abundances, and fruiting cycles of its hosts and local climatic factors (Harris and Lee, 1987; Eskafi and Kolbe, 1990). Medfly populations in Hawaii and Guatemala were classified as mostly temporary, with permanent populations residing only in areas where favored hosts produce fruit all year long, and where fly populations remain infrequent and small. Of the fruit sampled, $73-84 \%$ were uninfested, and most infested fruit (73-97\%) contained only one to three larvae (Harris and Lee, 1989). In Guatemala, Medflies had 10 to 12 generations per year in the coastal high plains (500-1900 m), but only two generations in 5 months at elevations $>2000 \mathrm{~m}$ (Eskafi and Kolbe, 1990). There is evidence that Medfly populations in Guatemala are susceptible to high intraspecific competition in coffee berries, with $81.2-99 \%$ of eggs laid not surviving to pupariation (Eskafi and Kolbe, 1990). In Guatemala, Medfly populations shared the same hosts with several Anastrepha spp. at el evations between 300 and $1900 \mathrm{~m}$, but only outcompeted Anastrepha ludens (Loew) in navel oranges at high elevations. In Costa Rica, of 7700 puparia obtained from 1595 fruit, 95.3\% were Anastrepha spp. and $4.7 \%$ were Medflies (J irón and Mexzon, 1989).

These biological attributes are similar to those of tephritid species described as late-sol itary trophic strategists by Zwölfer (1988) for thistle-infesting insect guilds in Europe. Headrick and Goeden (1990a) reported that Zwölfer's trophic strategies served well to define interspecific interactions among tephritids and their host complexes. Tephritid species that have such a trophic strategy are generalists infesting many host species throughout the entire geographical range of the tephritid. Locally these generalists may utilize only a few of their potential host species (cf. Eskafi and Kolbe, 1990). They typically lay few eggs, disperse them widely in hosts in a community, and are susceptible to high larval mortality in intra- and interspecific encounters within individual fruit (cf. Froggatt, 1909; Harris and Lee, 1989; Eskafi and Kolbe, 1990). The population dynamics of such tephritid species are also susceptible to fluctuations in community attributes, i.e., plant diversity, interspecific interactions, and abiotic factors. These allow such tephritids to become pestiferous in some areas when freed from their natural enemies, but barely noticeable in other areas, or subject them to localized extinction in still other areas (cf. Compere, 1912; Bess, 1953; Keiser et al., 1974; Harris and Lee, 1987; Hancock, 1984; Eskafi and Kolbe, 1990). Steck et al. (1986) studied Medfly populations in western tropical Africa and reported that at low el evations (200-300 m) Medfly was extremely rare in coffee, out-competed by another tephritid, Trirhithrum coffeae Bezzi, and occurred singly or in small numbers in a wide variety of hosts such as Chrysophyllum sp. (Star fruit or Star apple) and bell pepper (Capsicum frutescens grossum Bailey). However, at higher elevations (>1500 m), Medflies were somewhat more numerous in coffee and able to compete only when the climatically bettersuited competitor was not present. Steck et al. (1986) reported no parasitoids specific to Medfly.

Collating these biological data helps to explain the 
spotty distribution and extreme divergence in reports of the severity of Medfly as a pest and its invasion history. These data also help to explain why finding a specific parasitoid of Medfly has been difficult to date.

The history of biological control of Medfly. The first attempt at biological control of the Medfly was in Australia by George Compere, who was hired in 1902 by the government of Western Australia to search for the natural enemies of the Medfly. As told by Compere (1912), the Secretary of Agriculture of Western Australia, Lindley Cowen, was a difficult person to convince of the idea that natural enemies could control the Medfly. When Compere first arrived, he was asked which pest was the worst in Western Australia. Compere replied that it was the Medfly, without question. Cowen then explained that Western Australia had invested a tremendous effort during the preceding year (1901) to eradicate this pest. The government had condemned all orchards, picked all fruit, and boiled immature fruit. The government also employed inspectors to monitor orchards and also to remove and destroy fruit from urban gardens. Cowen was confident that they had starved out the Medfly and that all attention must now be refocused to find a control for the black scale (Saissetia ol eae(Bernard)). So in 1901 Compere sought to find natural enemies for the black scale in the Southern Hemisphere. By August of 1902, Mr. Cowen sent an urgent messageto Compere in Brisbane. It read that the Medfly had “. . . broken out worse than the historical plaque of Egyptian locusts, against all of the Herculean measures undertaken the previous year."! Compere (1912) noted that this came as no surprise to him and that while working on black scale he also continued to monitor and study the Medfly.

Compere then began a 10-year odyssey in search of Medfly natural enemies; however, during this time he was never able to ascertain the original home of the Medfly. Compere managed to rear parasitoids from other fruit flies while collecting in India and Ceylon, but was reluctant to send them to Western Australia, as he was convinced that natural enemies from the original home of the Medfly would be the only "weapon strong enough to thwart this nemesis" (Compere, 1912). However, while in São Paulo, Brazil, Compere changed his mind. He observed several species of braconid (Hymenoptera) parasitoids searching infested fruits. $\mathrm{He}$ also noted a staphylinid (Coleoptera) beetle predator of fruit fly larvae. The indiscriminate searching behavior of these polyphagous parasitoids and predators convinced him that it would be difficult to discover a host-specific parasitoid of the Medfly. He also was convinced that finding the original home of the Medfly should be abandoned. Thus, he sent all the species of fruit fly parasitoids that he discovered in India, Ceylon, and Brazil to Western Australia. According to Compere (1912), most growers in the São Paulo area never noticed the Medfly until he pointed it out. The paucity of Medfly in Brazil further convinced Compere that generalist natural enemies were providing control, and thus, these should be used in Australia. Compere shipped the hymenopterous parasitoids, Doryctobracon areol atus (Szepligeti) and Opius bellus Gahan, several undescribed staphylinid beetles, and an undescribed cynipid from Brazil toAustralia in 1904 and 1905. None of these agents became established. In 1906 and 1907, Compere brought Aceratoneuromyia indica (Silvestri) (Hymenoptera: Eulophidae) from southern India to Western Australia. He reared A. indica in a laboratory and released 250,000 or more in Western Australia between 1908 and 1910 (Compere, 1912). Despite Compere's optimism, this species also did not become established in Australia. In 1908, Compere sent 20,000 Ac. indica to South Africa from Australia, but again these parasitoids did not becomeestablished (Clausen, 1956).

Following Compere's work, Hawaii initiated a worldwide search for Medfly natural enemies. The Italian entomologist, Filipo Silvestri, was hired to search throughout Africa, as it was suspected that Africa was the most probable continent of origin. Silvestri's own account of this foreign exploration was published (Silvestri, 1914), and later expeditions are well documented (Clausen, 1956; Gilstrap and Hart, 1987; Wharton, 1989; Headrick and Goeden, 1995).

The best result for biological control efforts against the Medfly during the past 70 years has been the partial success achieved in Hawaii beginning with the introductions by Silvestri in 1913. A significant factor in reducing Medfly populations in Hawaii was the accidental introduction of the oriental fruit fly, Bactrocera dorsalis, and the intentional introduction of its parasitoids for biological control (Bess, 1953; Haramoto and Bess, 1970; Gilstrap and Hart, 1987; Wharton, 1989; Wong and Ramadan, 1990). More recently, biological control efforts in Hawaii have focused on the augmentative releases of Diachasmimorpha Iongicaudatus (Ashmead) (Hymenoptera: Braconidae) and other Opiinae braconids (Wong and Ramadan, 1990). Five parasitoid species established in Hawaii resulted from nearly a century of collecting on eight separate occasions in $>20$ countries around the world (Gilstrap and Hart, 1987; Wharton, 1989). However, none are hostspecific for Medfly, and three of the five were obtained from other African ceratitines (Gilstrap and Hart, 1987).

Most modern biological control programs initiated in other areas, i.e., the Mediterranean, Central America, and Australia, have used the five parasitoid species noted above rather than initiating searches for new species. The most commonly used species are D. Iongicaudatus, a parasitoid of southeast Asian dacines (Wharton and Gilstrap, 1983; Gilstrap and Hart, 1987) and Ac. indica, a parasitoid of Anastrepha and Dacus 
spp., that was first collected in India by Compere (1912). In Costa Rica, the parasitoids introduced for Medfly were subsequently found to be more frequently associated with Anastrepha spp., 5.5\% versus 10.5\% parasitization, respectively (J irón and Mexzon, 1989; Wharton and Gilstrap, 1983).

Hymenopterous parasitoids probably remain the best candidates for successful biological control of Medfly. The cryptic feeding habits of tephritid larval stages require natural enemies preadapted for tracking their hosts to the primary host plant, locating and ovipositing into egg or larval hosts within plant tissues, and phenologically synchronizing with their hosts. We feel that, in the future, biological control of the Medfly in any area of its occurrence would be enhanced with the use of target-specific parasitoids.

\section{Exploration for Medfly Biological Control}

Biological control should be part of California's longterm program for solving the Medfly problem. This opinion is not new, but warrants renewed consideration. Gilstrap and Hart (1987) and others have expressed a similar opinion in calling for a national program for biological control of exotic fruit flies. In-depth studies in the native range of any invaded pest are required to obtain evolutionarily adapted, target-specific natural enemies. This has yet to be undertaken for the Medfly. Thus, biological control research, which includes study of the biology, ecology, behavior, and natural enemies of the target pest, should be carried out in the native geographic range of the Medfly which is now known to be sub-Saharan, southeast Africa (Hancock, 1984, 1987).

Although Medflies have been reported as being rare in many parts of Africa, (Silvestri, 1914; Van Zwaluwenburg, 1937; Steck et al., 1986), local populations can be readily collected and studied in southeastern Africa (Hancock, 1984). A precept of biological control is that low population densities in areas of endemicity indicate good natural control. It is hoped that studies of the Medfly in Africa will reveal new target-specific parasitoids of the type needed for biological control of Medfly in California and el sewhere (Myers et al., 1989).

\section{ACKNOWLEDGMENTS}

We thank Gordon Gordh for his earlier comments and discussions which initially fostered the writing of this paper, and Frank Gilstrap, Tim Paine, J eff Teerink and two anonymous reviewers for their hel pful comments on early drafts of this paper.

\section{REFERENCES}

Annecke, D. P., and Moran, V. C. 1982. "Insects and Mites of Cultivated Plants in South Africa." Butterworths, Durban/Pretoria, South Africa.
Back, E. A. 1917. Danger of Introducing Fruit Flies into the United States. U. S. Department of AgricultureYearbook, pp. 185-196.

Bess, H. A. 1953. Status of Ceratitis capitata in Hawaii following the introduction of Dacus dorsalis and its parasites. Proc. Hawaii. Entomol. Soc. 15, 221-234.

California Department of F ood and Agriculture (CDFA) 1993. California Agricultural Statistical Review, 1992.

California Department of F ood and Agriculture (CDFA) 1994. Eradication of Medfly from California 1994-1995 Workplan.

Carey, J. R., and Dowell, R. V. 1989. Exotic fruit fly pests and California agriculture. Calif. Agric. 43(5/6), 38-40.

Carey, J. R. 1991. Establishment of the Mediterranean fruit fly in California. Science 253, 1369-1373.

Carey, J . R. 1992. The Mediterranean fruit fly in California: Taking stock. Calif. Agric. 46(1), 12-17.

Christenson, L. D., and Stone, W. E. 1956. Mediterranean fruit fly invades Costa Rica. Calif. Citrogr. 41, 123.

Clausen, C. P. 1956. Biological control of fruit flies. J . Econ. Entomol . 49, 176- 178.

Compere, G. 1912. A few facts concerning the fruit flies of the world. Calif. Agric. Monogr. Bull. 1, 307-370, 842-845, 907-911, 929-932.

Cunningham, R. T., Routhier, W., Harris, E. J ., Cunningham, G., Tanaka, N., J ohnson, L., Edwards, W. and Rosander, R. 1980. A case study: Eradication of the Medfly by sterile male release. Citrograph 65, 63-69.

Eskafi, F. M., and Kolbe, M. E. 1990. Infestation patterns of commonly cultivated, edible fruit species by Ceratitis capitata and Anastrepha spp. (Diptera: Tephritidae) in Guatemala and their relationship to environmental factors. Environ. Entomol. 19, 13711380.

Foote, R. H., Blanc, F. L., and Norrbom, A. L. 1993. "Handbook of the Fruit Flies (Diptera: Tephritidae) of America North of Mexico." Cornell Univ. Press, Ithaca/London.

Froggatt, W. W. 1909. Parasitic and I njurious I nsects. Department of Agriculture Report, New South Wales.

Gilstrap, F. E., and Hart, W. G. 1987. Biological control of the Mediterranean fruit fly in the United States and Central America. U. S. Department of AgricultureARS-56, pp. 1-64.

Goeden, R. D. 1987. Host-plant relations of native Urophora spp. (Diptera: Tephritidae) in southern California. Proc. Entomol. Soc. Wash. 89, 269-274.

Goeden, R. D. 1988a. Life history of Trupanea imperfecta (Coquillett) on Bebbia juncea (Bentham) Greene in the Colorado Desert of southern California (Diptera: Tephritidae). Pan-Pacific Entomol. 64, 345-351.

Goeden, R. D. 1988b. Gall formation by the capitulum-infesting fruit fly, Tephritis stigmatica (Diptera: Tephritidae). Proc. Entomol. Soc. Wash. 90, 37-43.

Goeden, R. D. 1990a. Life history of Eutreta diana (Osten Sacken) on Artemisia tridentata Nuttall in southern California (Diptera: Te phritidae). Pan-Pacific Entomol . 66, 24-32.

Goeden, R. D. 1990b. Notes on the life history of Eutreta simplex Thomas on Artemisia Iudoviciana Nuttall in southern California (Diptera: Tephritidae). Pan-Pacific Entomol . 66, 33-38.

Goeden, R. D., and Headrick, D. H. 1990. Notes on the biology and immature stages of Stenopa affinis Quisenberry (Diptera: Tephritidae). Proc. Entomol. Soc. Wash. 92, 641-648.

Goeden, R. D., and Headrick, D. H. 1991a. Life history and descriptions of immature stages of Tephritis baccharis (Coquillett) on Baccharis salicifolia (Ruiz \& Pavon) Persoon in southern California (Diptera: Tephritidae). Pan-Pacific Entomol . 67, 86-89.

Goeden, R. D., and Headrick, D. H. 1991b. Notes on the biology, hosts and immature stages of Tomoplagia cressoni Aczél in southern 
California (Diptera: Tephritidae). Proc. Entomol. Soc. Wash. 93, 549-558.

Goeden, R. D., and Headrick, D. H. 1992. Life history and descriptions of immature stages of Neaspilota viridescens Quisenberry (Diptera: Tephritidae) on nativeAsteraceae in southern California. Proc. Entomol. Soc. Wash. 94, 59-77.

Goeden, R. D., Headrick, D. H., and Teerink, J . A. 1993. Life history and descriptions of immature stages of Tephritis arizonaensis Quisenberry on Baccharis sarothroides Gray in southern California (Diptera: Tephritidae). Proc. Entomol. Soc. Wash. 95, 210-222.

Goeden, R. D., Headrick, D. H., and Teerink, J . A. 1994a. Life history and descriptions of immature stages of Procecidochares flavipes Aldrich on Baccharis sarothroi des in southern California (Diptera: Tephritidae). Proc. Entomol. Soc. Wash. 96, 288-300.

Goeden, R. D., Headrick, D. H., and Teerink, J . A. 1994b. Life history and description of immature stages of Paroxyna genalis (Thomson) (Diptera: Tephritidae) on nativeAsteraceae in southern California. Proc. Entomol. Soc. Wash. 96, 612-629.

Green, J . F., Headrick, D. H., and Goeden, R. D. 1993. Life history and description of immature stages of Procecidochares stonei Blanc \& Foote on Viguiera spp. in southern California (Diptera: Tephritidae). Pan-Pacific Entomol . 69, 18-32.

Hancock, D. L. 1984. Ceratitinae (Diptera: Tephritidae) from the Malagasy subregion. J . Entomol. Soc. South Africa 47, 277-301.

Hancock, D. L. 1985. Two new species of African Ceratitinae (Diptera: Tephritidae). Arnoldia Zimb. 9, 291-297.

Hancock, D. L. 1987. Notes on some African Ceratitinae (Diptera: Tephritidae), with special reference to the Zimbabwean fauna. Trans. Zimb. Sci. Assoc. 63, 47-57.

Haramoto, F. H., and Bess, H. A. 1970. Recent studies on the abundance of the Oriental and Mediterranean fruit flies and the status of their parasites. Proc. Hawaii. Entomol. Soc. 20, 551-566.

Hardy, D. E. 1973. The Fruit Flies (Tephritidae-Diptera) of Thailand and Bordering Countries. Pacific I nsects Monograph 31.

Hardy, D. E. 1974. The Fruit Flies of the Philippines (Diptera: Tephritidae). Pacific Insects Monograph 32.

Harris, E. J ., and Lee, C. Y. L. 1987. Seasonal and annual distribution of the Mediterranean fruit fly (Diptera: Tephritidae) in Honolulu and suburban areas of Oahu, Hawaii. Environ. Entomol. 16, 1273-1282.

Harris, E. J ., and Lee, C. Y. L. 1989. Development of Ceratitis capitata (Diptera: Tephritidae) in coffee in wet and dry habitats. Environ. Entomol. 18, 1042-1049.

Hawkes, G. R., and Stiles, M. C. 1985. Differential perceptions between citizens and scientists regarding pesticide use. In "Pest Control: Operations and Systems Analysis in Fruit Fly Management" (M. Mangel, J. R. Carey, and R. E. Plant, Eds.). SpringerVerlag, Berlin.

Headrick, D. H., and Goeden, R. D. 1990a. Resource utilization by larvae of Paracantha gentilis Hering (Diptera: Tephritidae) in Cirsium thistle capitula. Proc. Entomol. Soc. Wash. 91, 594-603.

Headrick, D. H., and Goeden, R. D. 1990b. Life history of Paracantha gentilis (Diptera: Tephritidae). Ann. Entomol. Soc. Am. 83, 776785.

Headrick, D. H., and Goeden, R. D. 1991. Life history of Trupanea californica Malloch (Diptera: Tephritidae) on Gnaphalium spp. (Asteraceae) in southern California. Proc. Entomol. Soc. Wash. 93, 559-570.

Headrick, D. H., and Goeden, R. D. 1995. Relationships of biological control to the Medfly eradication program in southern California, In "The Mediterranean Fruit Fly in California: Defining Critical Research" (J . Morse, R. Metcalf, J . Carey, and R. Dowell, Eds.), pp. 59-70. College of Natural and Agricultural Sciences, University of California, Riverside.
Headrick, D. H., Goeden, R. D., and Teerink, J . A. 1993. Life history and description of immature stages of Aciurina thoracica Curran (Diptera: Tephritidae) on Baccharis sarothroides Gray in southern California. Ann. Entomol. Soc. Am. 86, 68-79.

Headrick, D. H., Goeden, R. D., and Teerink, J . A. 1995. Life history and description of immature stages of Euaresta stigmatica (Diptera: Tephritidae) on Ambrosia spp. in southern California (Asteraceae). Ann. Entomol. Soc. Am. 87, 8-71.

Hendel, F. 1912. H. Sauter's Formosa-Ausbeute: Genus Dacus. Entomology 1(Suppl.), 13-24.

J irón, L. F., and Mexzon, R. G. 1989. Parasitoid hymenopterans of Costa Rica: Geographical distribution of the species associated with fruit flies (Diptera: Tephritidae). Entomophaga 34, 53-60.

Keiser, I., Kobayashi, R. M., Miyashita, D. H., Harris, E. J ., Schneider, E. L., and Chambers, D. L. 1974. Suppression of the Mediterranean fruit flies by oriental fruit flies in mixed infestations in guava. J . E con. Entomol . 67, 355-360.

Liquido, N. J ., Cunningham, R. T., and Nakagawa, S. 1990. Host plants of Mediterranean fruit fly (Diptera: Tephritidae) on the Island of Hawaii (1949-1985 survey). J. Econ. Entomol. 83, 1863-1878.

Lorraine, H., and Chambers, D. L. 1989. Eradication of exotic species: Recent experiences in California. In "World Crop Pests: Fruit Flies, Their Biology, Natural Enemies and Control" (A. S. Robinson and G. Harper, Eds.), Vol. 3B, pp. 399-410. Elsevier, Amsterdam.

MacLeay, W. S. 1829. Notice of Ceratitis citriperda, an insect very destructive to orange. Zool. J . 4, 475-482.

McDonald, P. T. 1987. Influence of prior egg-laying experience on choice of host fruits for oviposition by Mediterranean fruit fly Ceratitis capitata Wiedemann. Proc. Hawaii. Entomol Soc. 27, 121-124.

Mclnnis, D. O., Tam, S., Grace, C., and Miyashita, D. 1994. Population suppression and sterility rates induced by variable sex ratio, sterile insect releases of Ceratitis capitata (Diptera: Tephritidae) in Hawaii. Ann. Entomol. Soc. Am. 87, 231-240.

Metcalf, R. L. 1995. The need for research on exotic pests in California. In "The Mediterranean Fruit Fly in California: Defining Critical Research" (J . Morse, R. Metcalf, J . Carey, and R. Dowell, Eds.), pp. 59-70. College of Natural and Agricultural Sciences, University of California, Riverside.

Munro, H. K. 1935. Observations and comments on the Trypetidae of Formosa. Arb. Physiol. Entomol . 2, 195-271.

Myers, J. H., Higgins, C., and Kovacs, E. 1989. How many insect species are necessary for the biological control of insects. Environ. Entomol. 18, 541-547.

Newell, W. 1930. The Mediterranean fruit fly situation. J . Econ. Entomol. 23, 512-523.

Ortiz, G., Liedo, P., Reyes, J ., Schwartz, A., and Hendrichs, J . 1984. Mediterranean fruit fly Ceratitis capitata: Present status of the eradication program in southern Mexico. In "Fruit Flies of Economic Importance" (R. Cavallora, Ed.), Vol. 84. pp. 101-111. Gower, Brookfield, VT.

Riley, C. V., and Howard, L. O. 1891. Insect Life. U. S. Department of Agriculture, Division of Entomology Per. Bulletin, Vol. 3, pp. 5-8.

Sheppard, W. S., Steck, G. J ., and McPheron, B. A. 1992. Geographic populations of the Medfly may be differentiated by mitochondrial DNA variation. Experientia 48, 1010-1013.

Shiraki, T. 1933. A systematic study of Trypetidae in the J apanese Empire. Mem. Fac. Sci. Agric. Taihoku Imp. Univ. 8, 1-509.

Siebert, J. B., and Pradhan, J. 1990. The potential impact of the mediterranean fruit fly, Ceratitis capitata (Wied.), upon establishment in California: An update. California Agricultural Experiment Station Working Paper No. 547.

Siebert, J . B. 1994. Economic impact of an Embargo by J apan, Korea, 
Taiwan, and Hong Kong of selected California Exports due to a Mediterranean fruit fly infestation. Department of Agricultural and Resource E conomics, University of California Berkeley.

Silvestri, F. 1914. Report on an expedition to Africa in search of the natural enemies of fruit flies (Trupaneidae) with descriptions, observations and biological notes. Territory of Hawaii, Board of Agriculture and Forestry Division of Entomology Bulletin Vol. 3, 1-176.

Steck, G. J ., Gilstrap, F. E., Wharton, R. A., and Hart, W. G. 1986. Braconid parasitoids of Tephritidae (Diptera) infesting coffee and other fruits in west-central Africa. Entomophaga 31, 59-67.

Steiner, L. F., Rohwer, G. G., Ayers, E. L., and Christenson, L. D. 1961. The role of attractants in the recent Mediterranean fruit fly eradication program in Florida. J . Econ. Entomol. 54, 30-35.

Van Zwaluwenburg, R. H. 1937. West African notes. The Hawaiian Planters' Record. 41, 57-83.

Vargas, R. I., Harris, E. J ., and Nishida, T. 1983. Distribution and seasonal occurrence of Ceratitis capitata (Wiedemann) (Diptera: Tephritidae) on the island of Kauai in the Hawaiian Islands. Environ. Entomol. 12, 303-310.

Weinland, H. A. 1912. The present fruit fly situation and some results of the Hawaiian campaign. Calif. Agric. Monogr. Bull. 1, 845-852.

Wharton, R. A. 1989. Classical biological control of fruit-infesting Tephritidae. In "World Crop Pests: Fruit Flies, Their Biology, Natural Enemies and Control" (A. S. Robinson and G. Harper, Eds.), Vol. 3B, pp. 303-313.
Wharton, R. A., and Gilstrap, F. E. 1983. Key to and status of opiine braconid (Hymenoptera) parasitoids used in biological control of Ceratitis and Dacus s. I. (Diptera: Tephritidae). Ann. Entomol. Soc. Am. 76, 721-742.

White, I. M., and Elson-Harris, M. M. 1992. "Fruit Flies of Economic Significance: Their Identification and Bionomics," C.A.B. International, Wallingford, UK.

Whittier, T. S., Kaneshiro, K. Y., and Prescott, L. D. 1992. Mating behavior of Mediterranean fruit flies (Diptera: Tephritidae) in a natural environment. Ann. Entomol. Soc. Am. 85, 214- 218.

Wong, T. T. Y., and Ramadan, M. M. 1990. Mass-rearing biology of larval parasitoids (Hymentoptera: Braconidae: Opiinae) of tephritid fruit flies (Diptera: Tephritidae) in Hawaii. In "Advances in Insect Rearing for Research and Pest Management" (T. E. Anderson and N. C. Leppla, Eds.).

Yokoyama, V. Y., Miller, G. T., and Hartsell, P. L. 1992. Pest-free period and methyl bromidefumgation for control of wal nut husk fly (Diptera: Tephritidae) in stone fruits exported to New Zealand. Environ. Entomol . 85, 1-7.

Zadig, D. 1992. Plant quarantines: domestic strategies yield to international policies. Calif. Agric. 46(1), 9-11.

Zia, Y. 1937. Study on the Trypetidae or fruit-flies of China. Sinensia 8, 103-219.

Zia, Y. 1938. Trypetidae of N orth China. Sinensia 9, 1-172.

Zwölfer, H. 1988. Evolutionary and ecological relationships of the insect fauna of thistles. Annu. Rev. Entomol. 33, 103-122. 